\title{
National research for health system mapping in 5 countries in the Eastern Mediterranean Region and perspectives on strengthening the systems
}

Sir,

\section{Background}

The importance given to developing national systems for research for health is increasing rapidly around the world, especially following the Global Ministerial Meeting on Research for Health, held in Bamako, Mali, in 2008.

In 2004, the Research, Policy \& Cooperation Unit (RPC) of the World Health Organization's Regional Office for the Eastern Mediterranean (WHO/EMRO) published the results of a National Health Research System (NHRS) analysis that it had undertaken in 5 countries of the WHO Eastern Mediterranean Region [1].

In 2007, a similar study was initiated to assess the NHRS in 10 other countries in the WHO Eastern Mediterranean Region [2]. The 10-country study was a collaborative effort between the EMRO/RPC, the Council on Health Research for Development (COHRED), and the Health Ministers Council of the Gulf Cooperation Council States (GCC).

\section{Mapping}

Tocomplementtheseprevious 2 studies, WHO/EMRO supported COHRED to extend the NHRS mapping study to the remaining 8 member countries in the Region to be carried in 2009/2010. Of the 8 countries invited, 5 responded: Afghanistan, Iraq, Pakistan, Palestine and the Syrian Arab Republic.

Equipped with the NHRS-assessment tool developed by COHRED, each participating country carried out their own assessment in the period leading up to presenting their results in a meeting held in Cairo, 20-21 September 2010, hosted by Egypt's National Research Centre (NRC), and organised by COHRED and the New
Partnership for Africa's Development (NEPAD) North Africa Biosciences Network at NRC/Cairo. Focal points from 3 of the 5 participating countries, i.e. Afghanistan, Pakistan and Palestine, were able to provide updated information describing their own NHRS. Key regional actors that included Egypt's Ministry for Scientific Research and Ministry of Health and Population, as well as USAID's Health and Nutrition group, and researchers from NRC and other Egyptian institutions met to review the results from the 3 studies, extract lessons, and discuss the next steps to strengthen research for health and health research systems in the Region. The group also identified potentially interested partners and other resources needed to facilitate implementation of the next steps.

\section{Findings}

The main findings resulting from this initial mapping effort can be summarized as follows:

- All countries have a designated structure in their ministries of health which has the overall responsibility for the governance of national health research. These structures are monitored by executive managers in Afghanistan and Palestine. In Pakistan, there is an elected Board of Governors constituted of federal divisions.

- Palestine and Iraq do not conduct a formal evaluation of health research. The Syrian Arab Republic began such evaluation in 2009. The other countries have an annual evaluation. Evaluation reports are transmitted to various authorities but there is no information about the content, the quality of these reports, nor about the actions taken on negative evaluations.

- There is no substantive legislation to guide health research in any of the 5 countries. Some acts or restrictions deal only with ethics or value aspects that differ between countries.

- A health research plan has been developed in both Afghanistan and $\mathrm{Pa}$ kistan and includes a strategic and policy vision. The Syrian Arab Republic is adopting the WHO/EMRO cooperation development process as a basis for planning. There is no formal strategic or policy plan in Iraq or Palestine. All the countries have national health priorities, while Pakistan and the Syrian Arab Republic also have clearly defined health research priorities. It is not clear if these are widely known inside and outside the countries.

\section{The way forward}

Almost all countries in the WHO Eastern Mediterranean Region (19/22) now have at least a baseline assessment that can be and has already been used by national decision-makers to strengthen their health research management and governance system. In fact, all low- and middle-income countries will benefit from more efficient management of NHRS and the adoption of effective national health research policies [3].

Providing evidence to and engaging policy-makers and other stakeholders in research priority-setting increases the likelihood of the utilization of research evidencebypolicy-makers. This has been shown in Tunisia, which undertook a comprehensive national health research priority-setting effort in 2008, the results of which are currently used by the Ministry of Health [4]. Except for a few initiatives [5], no other previous efforts have been undertaken to set priorities for health policy and systems research in countries of the Middle East.

It is clear that collaboration is key to facilitate national improvements and 
regional collaboration and to increase available funding for health research. COHRED and NEPAD will encourage countries, organizations and decision-makers to develop benchmarks of high performing NHRS that can meaningfully improve the health status of the population and reduce inequities.
There is both an opportunity and an urgent need to support further development of NHRS in countries of the WHO's Eastern Mediterranean Region. Follow-up action between countries, WHO/EMRO, COHRED and NEPAD is envisaged for 2011 - the assessments having been completed, the time for action has arrived.

\section{Acknowledgements}

We acknowledge the support of NEPAD Agency and the Egyptian National Research Centre for the organization of the meeting, and the financial and technical support of WHO/EMRO for the conduct of the study.

\section{References}

1. A study of national health research systems in selected countries of the WHO Eastern Mediterranean Region. Cairo World Health Organization's Regional Office for the Eastern Mediterranean, 2004.

2. Kennedy A et al. National health research system mapping in 10 Eastern Mediterranean countries. Eastern Mediterranean Health Journal, 2008, 14(3):502-517.

3. Pang T et al. Knowledge for better health: a conceptual framework and foundation for health research systems. Bulletin of the World Health Organization, 2003, 81(11):815-820.
4. IJsselmuiden C, Ghannem H, Bouzouaïa N. Développement du système de recherche en santé: analyse et etablissement des priorités en Tunisie [Development of health research system: analysis and defining priorities in Tunisia]. La Tunisie Médicale, 2009, 87(1):1-2.

5. El-Jardali F et al. Eliciting policymakers' and stakeholders' opinions to help shape health system research priorities in the Middle East and North Africa region. Health Policy and Planning, 2010, 25(1):15-27.

Hassen Ghannem

Council on Health Research for Development (COHRED), Geneva, Switzerland (ghannem@cohred.org)

Department of Epidemiology, Faculty of Medicine, University of Sousse, Tunisia

Francisco Becerra-Posada

Council on Health Research for Development (COHRED), Geneva, Switzerland (Becerra@cohred.org)

Carel IJsselmuiden

Council on Health Research for Development (COHRED), Geneva, Switzerland (carel@cohred.org)

University of KwaZulu-Natal, Pietermaritzburg, South Africa

Iman Helwa

Department of Immunogenetics, National Research Centre, Cairo, Egypt (helwa1971@yahoo.com)

Sylvia de Haan

Council on Health Research for Development (COHRED), Geneva, Switzerland (dehaan@cohred.org)

On behalf of the working group:

Afghanistan: Dr Mir Lais Mustafa, Director Research, Afghan Public Health Institute (APHI)

Iraq: Dr Ohan Faraj Yonan, Head of Research Unit, Ministry of Health

Pakistan: Dr Huma Qureshi, Executive Director, Pakistan Medical Research Council

Palestine: Dr. Intisar Alem, Director of Research and Surveillance, Ministry of Health Nablus/ West Bank

Syrian Arab Republic: Dr Ghada Bsiki, Director of Health Research Program, Ministry of Public Health 